\title{
Princípios de biossegurança aplicados aos laboratórios de ensino universitário de microbiologia e parasitologia
}

\author{
Principles of biosafety applied to microbiology and parasitology laboratories in universities
}

\author{
Luis Antônio Sangioni ${ }^{\mathrm{I}}$ Daniela Isabel Brayer Pereira ${ }^{\mathrm{II}}$ Fernanda Silveira Flores Vogel $^{\mathrm{I}}$ \\ Sônia de Avila Botton ${ }^{*}$
}

\section{- REVISÃO BIBLIOGRÁFICA -}

\section{RESUMO}

Os laboratórios de ensino de microbiologia $e$ parasitologia nas universidades brasileiras são ambientes em que as atividades integradas, envolvendo ensino, pesquisa e extensão, demandam a convivência de pessoas, agentes e amostras biológicas, equipamentos, reagentes e resíduos num mesmo espaço, sendo inevitável a exposição das pessoas aos diferentes riscos. As atividades realizadas nesses laboratórios necessitam empregar as normas de segurança; pois, uma vez que o fator humano é susceptível aos acidentes, os programas de educação em biossegurança são imprescindiveis. Entretanto, para que esses programas sejam efetivos, é necessário que os usuários estejam devidamente informados acerca dos princípios de biossegurança, bem como aptos a colocá-los em prática de maneira correta, a fim de garantir a segurança dos profissionais, acadêmicos e do meio ambiente. Esta revisão compila os principais aspectos da biossegurança relacionados aos princípios e à classificação dos riscos, dos agentes biológicos e dos níveis de contenção laboratorial, bem como aborda as boas práticas laboratoriais nos laboratórios de ensino, pesquisa e extensão em microbiologia e parasitologia.

Palavras-chave: risco, segurança, educação em biossegurança.

\section{ABSTRACT}

The teaching laboratories of microbiology and parasitology in Brazilian universities are places where the integrated activities of teaching, research and extension are performed and require the coexistence in the same space, persons, biological agents and samples, equipment, reagents and waste, and where is inevitable the exposure of people to the different risks. The laboratorial activities practiced in Brazilian universities require the need for safety standards, since the human factor is likely the causes of accidents in laboratories, educational programs in biosafety become indispensable to the prevention of risks. However, for an education program become effective is necessary that the users are fully informed about the biosafety principles, as well as able to practice them properly to ensure the safety of all professionals, academics and the environment. This article compiles the main aspects related to the principles of biosafety, risk classification of biological agents and levels of biocontainment, and addresses the issues regarding safety equipment and good laboratory practices applied to the teaching laboratories in microbiology and parasitology.

Key words: risk, safety, education in biosafety.

\section{INTRODUÇÃO}

A biossegurança pode ser definida como o conjunto de ações voltadas para a prevenção, minimização ou eliminação de riscos inerentes às atividades de pesquisa, produção, ensino, desenvolvimento tecnológico e prestação de serviços, visando à saúde do homem, dos animais, à preservação do meio ambiente e à qualidade dos resultados (TEIXEIRA \& VALLE, 2010). No Brasil, existem duas vertentes da biossegurança: a legal e a praticada. A primeira está voltada à manipulação de organismos

'Departamento de Medicina Veterinária Preventiva, Centro de Ciências Rurais (CCR), Universidade Federal de Santa Maria (UFSM), Avenida Roraima, 1000, prédio 44, sala 5007, 97105-900, Camobi, Santa Maria, RS, Brasil. E-mail: sabott20@gmail.com. *Autor para correspondência.

"IDepartamento de Microbiologia, Instituto de Biologia, Universidade Federal de Pelotas (UFPel), Pelotas, RS, Brasil. 
geneticamente modificados (OGMs) e de células tronco, regulamentada pela Lei no 11.105/05. A segunda, está relacionada aos riscos químicos, físicos, biológicos, ergonômicos e de acidentes encontrados nos ambientes laborais, amparada principalmente pelas normas regulamentadoras do Ministério do Trabalho e Emprego (MTE), Resoluções da Agência Nacional de Vigilância em Saúde (ANVISA) e do Conselho Nacional do Meio Ambiente (CONAMA), entre outras (COSTA, 2005).

Os laboratórios de ensino de microbiologia e parasitologia nas universidades brasileiras são ambientes onde geralmente se realizam atividades de ensino, pesquisa e extensão de forma isolada ou em conjunto. Dessa forma, no mesmo espaço, convivem pessoas, equipamentos, reagentes, soluções, agentes e amostras biológicas e os resíduos gerados nessas atividades. Nesse contexto, pode haver a exposição das pessoas que neles trabalham, estudam e transitam pelos diferentes riscos, sejam eles: biológicos, químicos, físicos, ergonômicos e de acidentes; também gerando agravos para os animais e para meio ambiente (BRASIL, 2006). Sendo assim, é imprescindível o conhecimento da biossegurança a fim de preservar e/ ou minimizar os riscos nas atividades desenvolvidas. Em virtude de existirem poucas publicações científicas acerca da biossegurança nos laboratórios de ensino, pesquisa e extensão em microbiologia e parasitologia nas universidades brasileiras, este artigo busca informar os principais aspectos relacionados à biossegurança: os princípios, a classificação dos riscos, dos agentes biológicos e dos níveis de contenção laboratorial, bem como equipamentos de segurança e as boas práticas laboratoriais aplicadas.

\section{Princípios de biossegurança}

A biossegurança e a segurança biológica referem-se ao emprego do conhecimento, das técnicas e dos equipamentos, com a finalidade de prevenir a exposição do profissional, dos acadêmicos, dos laboratórios, da comunidade e do meio ambiente, aos agentes biológicos potencialmente patogênicos. Para isso, estabelecem as condições seguras para a manipulação e a contenção de agentes biológicos, incluindo: os equipamentos de segurança, as técnicas e práticas de laboratório, a estrutura física dos laboratórios, além da gestão administrativa (HIRATA \& MANCINI FILHO, 2002; BRASIL, 2006; MASTROENI, 2005).

Equipamentos de segurança: são considerados como barreiras primárias de contenção e, juntamente com as boas práticas em laboratório, visam à proteção dos indivíduos e dos próprios laboratórios, sendo classificados como equipamentos de proteção individual (EPI) e coletiva (EPC) (HIRATA \& MANCINI FILHO, 2002; BRASIL, 2006; PENNA et al., 2010).
Técnicas e práticas de laboratório: nos laboratórios, os indivíduos necessitam receber treinamento em relação às técnicas de biossegurança. Cada unidade deve desenvolver seu próprio manual de biossegurança, identificando os riscos e os procedimentos operacionais de trabalho, o qual deverá ficar à disposição de todos os usuários do local (BRASIL, 2006; PENNA et al., 2010).

Estrutura física do laboratório (barreiras secundárias): laboratórios de ensino de microbiologia e parasitologia apresentam características diferenciadas, devido à grande variabilidade de atividades realizadas em cada unidade. As barreiras secundárias incluem tanto o projeto como a construção das instalações e da infraestrutura do laboratório. A estrutura física laboratorial deve ser elaborada e/ou adaptada mediante a participação conjunta de especialistas, incluindo: os pesquisadores, técnicos do laboratório, arquitetos e engenheiros, de modo a estabelecer padrões e normas a fim de garantir as condições específicas de segurança de cada laboratório (BRASIL, 2006; SIMAS \& CARDOSO, 2008; PENNA et al., 2010).

Gestão administrativa: nesses locais, as práticas gerenciais e a organização das atividades são focos importantes de análise no estabelecimento de um programa de biossegurança. Em cada laboratório, é necessário realizar um levantamento detalhado dos agentes biológicos manipulados, das rotinas e das tecnologias empregadas, da infraestrutura disponível. Além disso, é imprescindível identificar os principais riscos e avaliar o nível de contenção que definirá as ações de biossegurança específicas a serem adotadas e que devem estar aliadas a um plano de educação continuada em biossegurança (HIRATA \& MANCINI FILHO, 2002). Ressalta-se que, para manipular os agentes biológicos com potencial infeccioso, deve-se conhecer as leis, dentre elas as internacionais, federais, estaduais e municipais relativas à biossegurança (BRASIL, 2010a). A evolução dos processos tecnológicos tem conduzido os profissionais ligados às atividades de ensino nos laboratórios à exposição de diversos riscos, especialmente os biológicos e químicos. De acordo com HIRATA \& MANCINI FILHO (2002), a avaliação e o manejo dos riscos são mandatórios à definição dos critérios e ações, visando a minimizar os riscos que podem afetar a saúde dos professores, técnicos, alunos e do meio ambiente.

Riscos nos laboratórios de ensino de microbiologia e parasitologia

O risco denota incerteza em relação a um evento futuro, sendo definido como a probabilidade de ocorrer um acidente causando algum tipo de dano, lesão 
ou enfermidade ou a probabilidade de concretização de um perigo (BRASIL, 2006). Essa probabilidade pode ser classificada como: alta: o dano poderá ocorrer sempre ou quase sempre; média: o dano poderá ocorrer em algumas ocasiões; ou baixa: o dano poderá ocorrer remotamente(SILVA, 2010). É importante ressaltar que a simples presença de um agente de risco em um laboratório não significa que, necessariamente, ocorrerá uma doença ou um acidente com os indivíduos que desenvolvem suas atividades no ambiente laboral. Em diferentes recintos laboratoriais, há situações de perigo e risco; portanto, é necessário sempre agir baseado no princípio básico da biossegurança, isto é, no princípio da precaução. A prevenção de acidentes demanda principalmente dos EPIs e EPCs adequados, treinamentos dos recursos humanos, adoção das normas e procedimentos de biossegurança (MASTROENI, 2005).

De acordo com HIRATA \& MANCINI FILHO (2002), os riscos estão classificados em: de acidente, ergonômicos, físicos, químicos e biológicos: a. Risco de acidente: considerado como sendo as situações de perigo que possam afetar a integridade, o bem estar físico e moral dos indivíduos presentes nos laboratórios. Nos laboratórios de ensino, compreendem: infraestrutura física com problemas (pisos lisos, escorregadios e instalações elétricas com fios expostos e/ou com sobrecarga elétrica); armazenamento ou descartes impróprios de substâncias químicas; dentre outras.b. Risco ergonômico: é qualquer ocorrência que venha a interferir nas características psicofisiológicas do indivíduo, podendo gerar desconforto ou afetando sua saúde. São consideradas as lesões determinadas pelo esforço repetitivo (LER) e as doenças osteomusculares relacionadas com o trabalho (DORT); como exemplo, cita-se: a pipetagem, pesagens, adoção de posturas físicas inadequadas durante a execução das atividades, etc. Além disso, o levantamento e o transporte manual de peso elevado, o ritmo e a carga horária excessivas de trabalho, a monotonia durante a realização de técnicas meticulosas que demandam maior atenção, também são considerados riscos ergonômicos relacionados às atividades nos laboratórios de ensino de microbiologia e parasitologia. c. Risco físico: é considerado como sendo as diversas formas de energia que os indivíduos estão expostos, tais como: ruído, vibrações, temperaturas extremas, radiações ionizantes e não ionizantes, ultra-som, materiais cortantes e pontiagudos. d. Risco químico: constitui-se em todas as substâncias, compostos ou produtos nas formas de gases, vapores, poeiras, fumaças, fumos, névoas ou neblinas, as quais possam penetrar no organismo pela via respiratória, por contato pela pele e mucosas ou absorvidas por ingestão. e. Risco biológico: abrange a manipulação dos agentes e materiais biológicos. São considerados agentes biológicos: vírus, bactérias, fungos, parasitas, príons, OGMs, além das amostras biológicas provenientes das plantas, dos animais e dos seres humanos, como, por exemplo, os tecidos, as secreções e as excreções (urina, fezes, escarros, derrames cavitários, sangue, células, matérias de biópsias e peças cirúrgicas, entre outros).

Tanto os agentes biológicos como os laboratórios de microbiologia e parasitologia recebem uma classificação em níveis de biossegurança de acordo com os critérios de avaliação dos riscos biológicos. Esses critérios são fundamentados principalmente na análise das seguintes características: virulência, modo de transmissão, resistência, concentração, volume, dose infectante e da origem dos agentes biológicos. Também são considerados critérios de avaliação dos riscos a disponibilidade de medidas profiláticas e de tratamento eficazes, caso aconteça a exposição dos indivíduos ao risco; além dos procedimentos técnicos realizados e dos fatores inerentes aos indivíduos que atuam nos laboratórios (BRASIL, 2006). Conforme o grau de patogenicidade, os agentes biológicos são classificados em:

Classe de risco 1: inclui os agentes biológicos que apresentam baixo risco para o indivíduo e para a coletividade, com baixa probabilidade de causar doença ao ser humano. Classe de risco 2: nessa classe estão inseridos os agentes biológicos que apresentam risco individual moderado para o indivíduo e com baixa probabilidade de disseminação para a coletividade. Podem causar doenças ao ser humano, entretanto, existem meios eficazes de profilaxia e/ou tratamento. Classe de risco 3: são os agentes biológicos que apresentam risco elevado para o indivíduo e com probabilidade moderada de disseminação para a coletividade. Podem causar doenças e infecções graves ao ser humano, entretanto nem sempre existem meios eficazes de profilaxia e/ou tratamento. Classe de risco 4: nesta estão incluídos os agentes biológicos que apresentam risco elevado para o indivíduo e com probabilidade elevada de disseminação para a coletividade. Apresenta grande poder de transmissibilidade de um indivíduo a outro. Podem causar doenças graves ao ser humano, ainda não existem meios eficazes para a sua profilaxia ou seu tratamento (BRASIL, 2006).

Níveis de biossegurança ou de contenção dos laboratórios de ensino em microbiologia e parasitologia

Para manipulação dos micro-organismos e parasitas pertencentes a cada uma das quatro classes 
de risco, devem ser atendidos alguns requisitos de segurança, conforme o nível de contenção necessário. Esses níveis de contenção são denominados níveis de biossegurança ou de biocontenção, sendo designados em ordem crescente (NB-1 a NB-4), pelo grau de proteção proporcionado ao pessoal do laboratório, meio ambiente e à comunidade (BRASIL, 2010b). Nível de biossegurança 1 (NB-1): necessário em atividades que envolvam os agentes biológicos da classe de risco 1. Representa um nível básico de contenção, que se fundamenta na aplicação das boas práticas laboratoriais (BPLs), na utilização de EPIs e EPCs e na adequação das instalações. Em geral, as atividades são realizadas sobre as bancadas. Nível de biossegurança 2 (NB-2): exigido para as atividades que envolvam os agentes biológicos da classe de risco 2 . O acesso ao laboratório deve ser restrito aos profissionais da área (professores, técnicos) e aos acadêmicos que estejam desenvolvendo atividades de ensino, pesquisa e extensão, mediante autorização do responsável técnico. Nível de biossegurança 3 (NB-3): aplicável aos locais em que forem desenvolvidas atividades com os agentes biológicos da classe de risco 3. Nível de biossegurança 4 (NB-4): exigido às atividades que manipulem os agentes biológicos da classe de risco 4 . Nos laboratórios NB-3 e NB-4, o acesso dos indivíduos deve ser restrito e utiliza-se um sistema de segurança altamente rigoroso. São designados aos laboratórios que desenvolvam atividades de diagnóstico e pesquisa de maior complexidade e nível de biocontenção (ENSERINK, 2000). Um resumo dos requisitos básicos exigidos em cada nível de biossegurança laboratorial está apresentado na tabela 1.

Atualmente, os laboratórios de ensino de microbiologia e parasitologia vinculados às instituições de ensino superior no Brasil equivalem aos NB-1 e NB-2. Nas atividades realizadas nesses laboratórios, há a manipulação de micro-organismos e parasitas de baixo risco biológico, estando associadas, principalmente, ao desenvolvimento das aulas práticas, das ações de extensão e de pesquisa. Em alguns laboratórios vinculados às instituições que oferecem serviços de diagnóstico e/ou pesquisa de agentes patogênicos, há maior risco biológico, sendo necessário adotar medidas de biossegurança mais restritas. Como citado por HIRATA \& MANCINI FILHO (2002), nesses ambientes, podem ser manuseados agentes biológicos classificados em nível 3, tais como: vírus da raiva, vírus da encefalomielite equina, vírus da imunodeficiência humana (HIV), Mycobacterium tuberculosis, Histoplasma capsulatum e outros patógenos transmissíveis por fluídos corporais e sangue. Esses laboratórios recebem a classificação NB-2, no entanto, necessitam instituir procedimentos padrões e BPLs preconizados para o NB-3.

Em relação à estrutura física, deve-se ressaltar que alguns laboratórios pedagógicos estão situados em prédios mais antigos, que inicialmente não foram projetados como estrutura laboratorial e antecederam os preceitos de biossegurança, revisados por PENNA et al. (2010). Todavia, devido à demanda das atividades de ensino, pesquisa e extensão, as instalações laboratoriais tiveram que ser adequadas a essas exigências. Contudo, a fim de atender as exigências reunidas nas resoluções e instruções normativas estabelecidas pela CTNBio e, com base na Lei Nacional de Biossegurança (BRASIL, 2005), as dependências desses laboratórios deverão ser revistas e readaptadas. De acordo com os níveis de biossegurança, as características dos laboratórios de microbiologia e parasitologia estão sintetizadas na tabela 2.

\section{Equipamentos de segurança: EPIs e EPCs}

EPI é todo o dispositivo de uso individual, destinado a proteger a saúde e a integridade física do trabalhador. A sua regulamentação está descrita na Norma Regulamentadora nº 06 (NR-06) do Ministério do Trabalho e Emprego (MTE). EPC, por sua vez, é todo o dispositivo que proporciona proteção a todos os profissionais expostos aos riscos no ambiente laboral.

Nos laboratórios de ensino superior de microbiologia e parasitologia, são imprescindíveis o emprego de EPIs e EPCs e o emprego das BPLs, a fim de minimizar os riscos e desempenhar um trabalho com maior segurança (HIRATA\& MANCINI FILHO, 2002; MASTROENI, 2005).

Os EPIs e EPCs básicos recomendados para uso nos laboratórios de ensino de microbiologia e parasitologia devem estar em conformidade com a Portaria MTB no 3.214, (BRASIL, 1978) e consistem em: i. EPIs para proteção da cabeça: óculos de segurança para prevenir os respingos nos olhos, os quais possam causar infecção, principalmente os provenientes das culturas de agentes e amostras biológicas, que possam ocasionar irritação nos olhos e outras lesões decorrentes da ação de soluções e reagentes usados no laboratório; partículas que possam ferir os olhos. Devem ser usados, também, protetores faciais destinados à proteção dos olhos e da face contra lesões produzidas por diversas partículas, respingos, vapores de produtos químicos e radiações luminosas intensas. Membros superiores: luvas e/ou mangas de proteção devem ser usados em trabalhos em que haja perigo de agravos provocados por: agentes biológicos oriundos dos diferentes materiais biológicos; materiais ou objetos pérfuro-cortantes; produtos químicos 
Tabela 1 - Principais requisitos para os níveis de segurança laboratorial.

\begin{tabular}{|c|c|c|c|c|}
\hline \multirow{2}{*}{ Requisitos } & \multicolumn{4}{|c|}{-------Nível de biossegurança-------- } \\
\hline & 1 & 2 & 3 & 4 \\
\hline Isolamento do laboratório & $\mathrm{N}$ & $\mathrm{N}$ & S & $\mathrm{S}$ \\
\hline Sala completamente vedada para a descontaminação & $\mathrm{N}$ & $\mathrm{N}$ & S & $\mathrm{S}$ \\
\hline $\begin{array}{l}\text { Áreas de escritórios designados à administração e pesquisa fora das instalações de } \\
\text { biocontenção }\end{array}$ & $\mathrm{N}$ & $\mathrm{N}$ & S & $\mathrm{S}$ \\
\hline Local para acondicionamento de roupas e objetos pessoais fora das áreas de biocontenção & $\mathrm{R}$ & $\mathrm{S}$ & $\mathrm{S}$ & $\mathrm{S}$ \\
\hline Refeitório fora da área de biocontenção & $\mathrm{S}$ & $\mathrm{S}$ & $\mathrm{S}$ & $\mathrm{S}$ \\
\hline $\begin{array}{l}\text { Símbolo de risco biológico afixado na porta de entrada e nas áreas de manipulação de } \\
\text { agentes biológicos }\end{array}$ & $\mathrm{N}$ & $\mathrm{S}$ & $S$ & $\mathrm{~S}$ \\
\hline Execução das atividades laboratoriais em dupla & $\mathrm{N}$ & $\mathrm{N}$ & $\mathrm{R}$ & $\mathrm{S}$ \\
\hline $\begin{array}{l}\text { Sistema para higienização e segurança: pias para lavagem das mãos com acionamento } \\
\text { mecânico ou automático e chuveiro e lava-olhos }\end{array}$ & $\mathrm{S}$ & $\mathrm{S}$ & S & $\mathrm{S}$ \\
\hline Adução do ar & $\mathrm{N}$ & $\mathrm{R}$ & $S$ & $\mathrm{~S}$ \\
\hline Sistema de ventilação controlada & $\mathrm{N}$ & $\mathrm{R}$ & S & $\mathrm{S}$ \\
\hline Exaustor com filtros de alta eficiência (High Efficiency Particulated Air - HEPA) & $\mathrm{N}$ & $\mathrm{N}$ & $\mathrm{S}$ & $\mathrm{S}$ \\
\hline Entrada com porta dupla & $\mathrm{N}$ & $\mathrm{N}$ & $\mathrm{S}$ & $\mathrm{S}$ \\
\hline Sistema de portas com travamento mecânico ou automático & $\mathrm{R}$ & $\mathrm{R}$ & S & $\mathrm{S}$ \\
\hline Câmara de vácuo (pressão negativa na área de biocontenção) & $\mathrm{N}$ & $\mathrm{N}$ & $S$ & $\mathrm{~S}$ \\
\hline Câmara de vácuo com ducha & $\mathrm{N}$ & $\mathrm{N}$ & $\mathrm{N}$ & $\mathrm{S}$ \\
\hline Antecâmara & $\mathrm{N}$ & $\mathrm{N}$ & S & - \\
\hline Antecâmara com chuveiros/duchas & $\mathrm{N}$ & $\mathrm{N}$ & S & $\mathrm{N}$ \\
\hline Tratamento dos efluentes & $\mathrm{R}$ & $\mathrm{R}$ & $S$ & $\mathrm{~S}$ \\
\hline Incineração dos resíduos após a esterilização & $\mathrm{N}$ & $\mathrm{N}$ & $\mathrm{R}$ & $\mathrm{S}$ \\
\hline In loco & $\mathrm{N}$ & $\mathrm{R}$ & $S$ & $\mathrm{~S}$ \\
\hline Em área separada, nas dependências do laboratório & $\mathrm{N}$ & $\mathrm{N}$ & $\mathrm{R}$ & $\mathrm{S}$ \\
\hline Contendo duas portas & $\mathrm{N}$ & $\mathrm{N}$ & $\mathrm{R}$ & $\mathrm{S}$ \\
\hline Classe I & $\mathrm{R}$ & $\mathrm{R}$ & - & - \\
\hline Classe II & $\mathrm{R}$ & $\mathrm{S}$ & S & - \\
\hline Classe III & - & - & $\mathrm{R}$ & $\mathrm{S}$ \\
\hline Circuito interno de imagem & $\mathrm{N}$ & $\mathrm{N}$ & $\mathrm{R}$ & $\mathrm{S}$ \\
\hline Registro pelas autoridades sanitárias nacionais & $\mathrm{N}$ & $\mathrm{N}$ & $S$ & $\mathrm{~S}$ \\
\hline Roupas de proteção com pressão positiva e ventilação & $\mathrm{N}$ & $\mathrm{N}$ & $\mathrm{N} / \mathrm{S}^{*}$ & $\mathrm{~S}$ \\
\hline Uso EPIs & $\mathrm{S}$ & $\mathrm{S}$ & $S$ & $\mathrm{~S}$ \\
\hline Cumprimento das BPLs & $\mathrm{S}$ & $\mathrm{S}$ & $\mathrm{S}$ & $\mathrm{S}$ \\
\hline Incineração dos resíduos após a esterilização & $\mathrm{N}$ & $\mathrm{N}$ & $\mathrm{N}$ & $\mathrm{S}$ \\
\hline
\end{tabular}

N- Não é mandatório; S- Uso é mandatório; R- Uso é recomendável. "Se houver risco de produção de aerossóis, é exigido o uso do traje de pressão positiva e ventilação associado à utilização de CSB classe II. Fonte: Adaptado de PENNA et al. (2010).

(corrosivos, cáusticos, tóxicos, solventes orgânicos, etc.); materiais ou objetos geradores de temperaturas extremas (aquecidos ou frios). Membros inferiores: calçado de proteção impermeável, solado liso e antiderrapante, sendo resistente aos agentes biológicos patogênicos; produtos químicos; umidade; riscos de acidentes (escorregões, tropeços e quedas). Tronco: vestimentas de proteção para atividades em que haja perigo de danos provocados especialmente por riscos de origem biológica, química, física, tais como: jalecos, aventais e macacões. Sistema respiratório: equipamentos de proteção respiratória (EPR) são os dispositivos usados para evitar a exposição aos diferentes agentes presentes nos laboratório de microbiologia e parasitologia, em concentrações prejudiciais à saúde dos usuários, de 
Tabela 2 - Resumo das características dos laboratórios de microbiologia e parasitologia de acordo com os níveis de biossegurança (NB).

\begin{tabular}{|c|c|c|c|c|c|}
\hline NB & Agente biológico & Procedimentos & $\begin{array}{l}\text { Equipamentos de segurança } \\
\text { (Barreira primária) }\end{array}$ & $\begin{array}{c}\text { Infraestrutura } \\
\text { (Barreira secundária) }\end{array}$ & Exemplos \\
\hline NB-1 & $\begin{array}{l}\text { Menor potencial } \\
\text { patogênico para } \\
\text { adultos sadios, } \\
\text { incluindo os não- } \\
\text { zoonóticos. }\end{array}$ & $\begin{array}{l}\text { Boas práticas } \\
\text { laboratoriais (BPL) } \\
\text { básicas são requeridas. }\end{array}$ & $\begin{array}{l}\text { Usar EPIs conforme a } \\
\text { atividade a ser } \\
\text { desenvolvida. }\end{array}$ & Bancada aberta. & $\begin{array}{l}\text { Vírus da: cinomose e } \\
\text { da hepatite canina; } \\
\text { bactérias e fungos } \\
\text { utilizados na indústria } \\
\text { alimentícia e } \\
\text { farmacêutica; entre } \\
\text { outros. }\end{array}$ \\
\hline NB-2 & $\begin{array}{l}\text { Infecções no } \\
\text { homem, existindo o } \\
\text { risco de ingestão e } \\
\text { inoculação } \\
\text { percutânea e mucosa } \\
\text { em laboratoristas. }\end{array}$ & $\begin{array}{l}\text { BPLs básicas, o acesso } \\
\text { ao recinto deve ser } \\
\text { limitado; sinalizar as } \\
\text { áreas de risco } \\
\text { biológico; } \\
\text { descontaminar o lixo e } \\
\text { resíduos; instituir } \\
\text { protocolos para } \\
\text { primeiros socorros. }\end{array}$ & $\begin{array}{l}\text { Cabines de segurança } \\
\text { biológica (CSB) de classe I } \\
\text { e II para manipular os vírus } \\
\text { e tudo o que produzir } \\
\text { aerossóis e derramamentos; } \\
\text { usar jalecos, luvas, proteção } \\
\text { facial, dependendo da } \\
\text { atividade. }\end{array}$ & $\begin{array}{l}\text { Assim como em NB- } \\
1 \text { e autoclave. }\end{array}$ & $\begin{array}{l}\text { Vírus da: } \\
\text { influenza, rubéola, } \\
\text { sarampo, caxumba; } \\
\text { Leptospira } \\
\text { interrogans,, } \\
\text { Staphylococcus } \\
\text { aureus; Candida } \\
\text { tropicalis, etc. } \\
\text { Em geral, os parasitas } \\
\text { são classificados } \\
\text { como agentes NB-2. }\end{array}$ \\
\hline NB-3 & $\begin{array}{l}\text { Exóticos ou } \\
\text { selvagens com } \\
\text { potencial de } \\
\text { transmissão por } \\
\text { aerossóis e de } \\
\text { provocar } \\
\text { enfermidade severa } \\
\text { e/ou letal }\end{array}$ & $\begin{array}{l}\text { Todas as BPLs adotas } \\
\text { no NB-2, e: o acesso } \\
\text { ao recinto deve ser } \\
\text { controlado; } \\
\text { descontaminar o lixo e } \\
\text { resíduos, bem como as } \\
\text { roupas usadas no } \\
\text { laboratório antes da } \\
\text { lavagem; coletar } \\
\text { periodicamente o soro } \\
\text { dos profissionais e } \\
\text { utilizar os } \\
\text { imunoprofiláticos } \\
\text { disponíveis. }\end{array}$ & $\begin{array}{l}\text { CSB de classe II e III para } \\
\text { manipular os vírus e tudo } \\
\text { que produzir aerossóis e } \\
\text { derramamentos; trajar } \\
\text { roupas específicas para uso } \\
\text { restrito no laboratório; EPIs } \\
\text { de acordo com a atividade a } \\
\text { ser desempenhada, assim } \\
\text { como uso de proteção } \\
\text { respiratória. }\end{array}$ & $\begin{array}{l}\text { NB-2 e: separação } \\
\text { física dos corredores } \\
\text { e das áreas de } \\
\text { circulação, portas } \\
\text { duplas com } \\
\text { fechamento } \\
\text { automatizado, fluxo } \\
\text { de ar direcional e } \\
\text { pressão negativa nos } \\
\text { recintos, sistema para } \\
\text { filtrar ar HEPA (High } \\
\text { Efficiency Particulate } \\
\text { Air). }\end{array}$ & $\begin{array}{l}\text { Herpes vírus dos } \\
\text { símios, hantavírus, } \\
\text { vírus da encefalite } \\
\text { equina venezuelana; } \\
\text { Mycobacterium } \\
\text { tuberculosis, } \\
\text { Histoplasma } \\
\text { capsulatum entre } \\
\text { outros. }\end{array}$ \\
\hline NB-4 & $\begin{array}{l}\text { Altamente perigosos } \\
\text { ou exóticos, } \\
\text { transmitidos por } \\
\text { aerossóis, } \\
\text { apresentando grande } \\
\text { risco de causar } \\
\text { morte. Ainda não } \\
\text { completamente } \\
\text { caracterizados }\end{array}$ & $\begin{array}{l}\text { BPL empregadas no } \\
\text { NB-3 e: trocar de } \\
\text { roupas antes de entrar } \\
\text { nas áreas de risco } \\
\text { biológico; banho antes } \\
\text { da saída do } \\
\text { laboratório; todo } \\
\text { material deve ser } \\
\text { descontaminado antes } \\
\text { da remoção. }\end{array}$ & $\begin{array}{l}\text { Todos os equipamentos do } \\
\text { NB-3, e: CSB III e/ou } \\
\text { vestimentas (macacão) com } \\
\text { pressão positiva em } \\
\text { associação com CSB II. }\end{array}$ & $\begin{array}{l}\text { NB-3 e: prédio } \\
\text { separado ou área } \\
\text { isolada com entrada e } \\
\text { saída de ar } \\
\text { controlada, sistema } \\
\text { de filtros HEPA, } \\
\text { pressão negativa, } \\
\text { sistema de } \\
\text { descontaminação } \\
\text { controlado, } \\
\text { autoclaves com dupla } \\
\text { abertura e os resíduos } \\
\text { depositados em } \\
\text { containers } \\
\text { específicos. }\end{array}$ & $\begin{array}{l}\text { Vírus Ebola, vírus de } \\
\text { Marburg, vírus sabiá, } \\
\text { vírus da febre } \\
\text { hemorrágica Criméia- } \\
\text { Congo, entre outros. }\end{array}$ \\
\hline
\end{tabular}

Fonte: Modificado a partir da NR-32 (BRASIL, 2005) e BRASIL (2006).

acordo com os limites estabelecidos na NR-6 do MTB (BRASIL, 1978), incluindo: máscaras autônomas de circuito aberto ou fechado para proteção das vias respiratórias. As máscaras do tipo cirúrgicas não são efetivas em proteger o indivíduo contra os aerossóis (http://www.anvisa.gov.br/divulga/public/ cartilha_mascara.pdf.). ii. EPCs: também devem seguir as especificações indicadas conforme a legislação 
vigente (BRASIL, 1978) e as instruções que constam nos manuais disponíveis (WHO, 2004; CDC, 2009) e incluem: sinalização de segurança: nos laboratórios de microbiologia e parasitologia, servem para indicar onde há presença dos riscos. Exemplo: símbolo de risco biológico afixado na porta de entrada nos locais de manipulação e armazenamento de agentes biológicos (a partir do NB-2); símbolos de líquidos inflamáveis, explosivos, produto tóxico, veneno, etc., para indicar presença de risco químico; os símbolos de elementos radioativos, apontando para risco físico; mapa de risco, sinais para as saídas de emergência, escadas, extintores de incêndio, faixas de demarcação, etc. Extintor de incêndio: o número, o tipo e a distribuição desses extintores devem estar adequados; sua manutenção e/ ou reposição devem ser periódicas, bem como o pessoal do laboratório deve ser treinado para o seu uso. Capela química: cabine construída de forma aerodinâmica, de maneira que o fluxo de ar ambiental não ocasione turbulências e correntes, reduzindo o perigo de inalação e a contaminação do operador e do ambiente. Borrifador de teto: sistema de segurança acionado pela elevação de temperatura, lançando fortes jatos de água no ambiente. Luz ultravioleta (UV): lâmpadas germicidas, com comprimento de onda ativo de 240nm. Devem estar presentes nas cabines de segurança biológica, tem ação efetiva por 15 minutos e o tempo médio de uso é aproximadamente de 3.000 horas. Pipetadores e pipetas mecânicos e automáticos: dispositivos de suç̧ão para pipetas e ponteiras, como: pera de borracha, pipetador automático, pipetas mono e multicanais, etc. Contenção para equipamentos como: homogeneizador, agitador, ultrassom, etc. Equipamentos produtores de aerossóis devem ser cobertos com anteparo autoclavável e, preferencialmente, abertos dentro das cabines de segurança biológica. Containers para desprezar os materiais contaminados e pérfuro-cortantes: precisam estar disponibilizados recipientes resistentes e autoclaváveis para desprezar os materiais que irão para o descarte. Conjunto (kit) de primeiros socorros: compostos por material comumente preconizado para socorro imediato e antídotos especiais para produtos tóxicos usados nos laboratórios de ensino de microbiologia e parasitologia. Chuveiro e lava-olhos: devem estar presentes em todos os laboratórios em perfeito estado de funcionamento e higienizado. Aágua para os lava-olhos deve ser preferencialmente filtrada. Cabine de segurança biológica (CSB): classes I e II (BRASIL, 2006).

Boas práticas laboratoriais (BPLs)

Conforme MASTROENI (2005) eARAÚJO

et al. (2009), as BPLs padrões constituem um conjunto de normas, procedimentos e atitudes de segurança, as quais visam a minimizar os acidentes que envolvem as atividades desempenhadas pelos laboratoristas, bem como incrementam a produtividade, asseguram a melhoria da qualidade dos serviços desenvolvidos nos laboratórios de ensino de microbiologia e parasitologia e, ainda, auxiliam a manter seguro o ambiente. A utilização das BPLs requer a aplicação do bom senso e prudência dos profissionais e acadêmicos ao desenvolver cada atividade. Cabe aos coordenadores e professores dos laboratórios de ensino de microbiologia e parasitologia o incentivo e a fiscalização da aplicação das normas e dos procedimentos padrões e específicos, permitindo, com isso, a manutenção de um ambiente seguro e confiável a toda equipe do laboratório. As BPLs padrões nos laboratórios de ensino de microbiologia e parasitologia devem ser conhecidas, aplicadas por todos os usuários e compreendem:

1. restringir o acesso de pessoas ao laboratório, somente os indivíduos autorizados pelos coordenadores e professores podem ingressar nos ambientes laboratoriais;

2. observar os princípios básicos de higiene, entre eles: manter as mãos limpas e unhas aparadas; sempre lavar as mãos antes e após vários procedimentos (manuseio de materiais biológicos viáveis; uso das luvas; antes de sair do laboratório; antes e após a ingestão dos alimentos e bebidas, etc.). Se não existirem pias no local, deve-se dispor de líquidos anti-sépticos para limpeza das mãos;

3. proibir: a ingestão e/ou o preparo de alimentos e bebidas, fumar, mascar chicletes, manipular lentes de contato, a utilização de cosméticos e perfumes, o armazenamento de alimentos para consumo nas áreas de manipulação de agentes biológicos e químicos. Em todos os laboratórios deve haver uma área designada como refeitório;

4. pipetar com a boca é expressamente proibido e jamais se deve colocar na boca objetos de uso no laboratório (canetas, lápis, borrachas, pipetas, entre outros);

5. utilizar calçados de proteção: fechados, confortáveis, com soldado liso e antiderrapante;

6. usar as luvas de procedimentos somente nas atividades laboratoriais e evitar tocar em objetos de uso comum;

7. trajar roupas de proteção durante as atividades laboratoriais, como: jalecos, aventais, macacões, entre outros. Essas vestimentas não devem ser usadas em outros ambientes fora do laboratório, como: escritório, biblioteca, salas de estar e refeitórios;

8. evitar o uso de qualquer tipo de acessórios/ adornos durante as atividades laboratoriais;

Ciência Rural, v.43, n.1, jan, 2013. 
9. manter os artigos de uso pessoal fora das áreas designadas às atividades laboratoriais;

10. organizar os procedimentos operacionais padrões (POP) para o manuseio dos equipamentos e técnicas empregados nos laboratórios;

11. garantir que a limpeza dos laboratórios (bancadas, pisos, equipamentos, instrumentos e demais superfícies) seja realizada regularmente antes e imediatamente após o término das atividades laboratoriais. Em caso de derramamentos, dependendo do tipo e quantidade de material biológico disseminado, pode-se empregar, para a descontaminação do local: álcool a $70 \%$ ou solução de hipoclorito de sódio, preferencialmente, a $10 \%$, deixando agir por 30 minutos e após remover com papel absorvente;

12. assegurar que os resíduos biológicos sejam descontaminados antes de ser descartados;

13. manusear, transportar e armazenar materiais (biológicos, químicos e vidrarias) de forma segura para evitar qualquer tipo de acidente. O manuseio de produtos químicos voláteis, metais, ácidos e bases fortes, entre outros, necessita ser realizado em capela de segurança química. As substâncias inflamáveis precisam ser manipuladas com extremo cuidado, evitando-se proximidade de equipamentos e fontes geradoras de calor;

14. usar os EPIs adequados durante o manuseio de produtos químicos;

15. identificar adequadamente todos os produtos químicos e frascos com soluções e reagentes, os quais devem conter a indicação do produto, condições de armazenamento, prazo de validade, toxidade do produto e outros;

16. acondicionar os resíduos biológicos e químicos em recipientes adequados, em condições seguras e encaminhá-los ao serviço de descartes de resíduos dos laboratórios para receberem o seu destino final;

17. afixar a sinalização adequada nos laboratórios, entre elas, incluir o símbolo internacional de "Risco Biológico" na entrada dos laboratórios a partir do NB-2;

18. instituir um programa de controle de roedores e vetores nos laboratórios;

19. evitar trabalhar sozinho no laboratório e jornadas de trabalho prolongadas;

20. providenciar treinamento e supervisão aos iniciantes nos laboratórios;

21. disponibilizar kits de primeiros socorros e promover a capacitação dos usuários em segurança e emergência nos laboratórios.

\section{CONCLUSÃO}

As atividades de ensino, pesquisa e extensão praticadas nos laboratórios de ensino de microbiologia e parasitologia das universidades brasileiras abrangem as diferentes áreas do conhecimento e no seu desenvolvimento existe a presença de riscos. Esse fato demanda a necessidade de normas de segurança destinadas à análise e desenvolvimento de estratégias para minimizá-los, sendo esta a principal função da biossegurança. A determinação dos níveis de contenção deve ser priorizada nos laboratórios das universidades, pois, com o surgimento de novas tecnologias, os procedimentos operacionais para a manipulação de agentes biológicos patogênicos deverão ser adequados para garantir a segurança dos profissionais, acadêmicos e do meio ambiente.

Devido ao fator humano estar implicado às causas de acidentes em laboratórios, o maior esforço deve estar direcionado aos aspectos de educação em biossegurança, que devem estar presentes no cotidiano das instituições de ensino. Salienta-se que alguns indivíduos tendem somente a levar em consideração a execução das atividades e menosprezar os riscos, sendo que esta postura não pode ser admitida em qualquer ambiente laboratorial. Para que um programa de educação em biossegurança seja efetivo, é necessário que todos os usuários dos laboratórios estejam devidamente informados acerca dos princípios de biossegurança, bem como aptos a colocá-los em prática de maneira correta, a fim de manter o ambiente seguro.

\section{REFERÊNCIAS}

ARAÚJO, S.A. et al. Manual de biossegurança: boas práticas no laboratórios de aulas práticas da área básica das ciências biológicas e da saúde. 2009. 100f. Disponível em: <http:// www.unp.br/arquivos/pdf/institucional/docinstitucionais/manuais/ manualdebiosseguranca.pdf $>$. Acesso em: 23 fev. 2012.

BRASIL. Lei no 11.105 , de 24 de março de 2005. Regulamenta os incisos II, IV e V do $\S 1$ o do art. 225 da Constituição Federal, estabelece normas de segurança e mecanismos de fiscalização de atividades que envolvam organismos geneticamente modificados - OGM e seus derivados, cria o Conselho Nacional de Biossegurança - CNBS, reestrutura a Comissão Técnica Nacional de Biossegurança - CTNBio, dispõe sobre a Política Nacional de Biossegurança - PNB, revoga a Lei no 8.974, de 5 de janeiro de 1995, e a Medida Provisória no 2.191-9, de 23 de agosto de 2001, e os arts. 5o, 6o $7^{\circ}, 8^{\circ}, 9^{\circ}, 10$ e 16 da Lei no 10.814 , de 15 de dezembro de 2003 , e dá outras providências. Diário Oficial da União, 28 de março de 2005. Disponível em: <http://www.planalto.gov.br/ccivil_03/_Ato2004-2006/ 2005/lei/L11105.htm>. Acesso em: 27 jun. 2011.

BRASIL. Biossegurança em laboratórios biomédicos e de microbiologia. Ministério da Saúde. Secretaria de Vigilância em Saúde. Departamento de Vigilância Epidemiológica. 3.ed. Brasília: Ministério da Saúde, 2006. 290p.

BRASIL. Portaria MTB no 3.214, de 08 de Junho de 1978. Aprova as Normas Regulamentadoras - NR - do Capítulo V, 
Título II, da Consolidação das Leis do Trabalho, relativas a Segurança e Medicina do Trabalho. Diário Oficial da União, 06 de julho de 1978. Disponível em: <http://portal.mte.gov.br/ data/files/8A7C816A33EF45990134335D0C415AD6/NR06\%20(atualizada)\%202011.pdf>. Acesso em: 13 de mar. 2012.

BRASIL. Diretrizes gerais para o trabalho em contenção com agentes biológicos. Ministério da Saúde. Secretaria de Ciência, Tecnologia e Insumos Estratégicos. Departamento de Ciência e Tecnologia. 3.ed. Brasília: Ministério da Saúde, 2010a. 70p.

BRASIL. Classificação de risco dos agentes biológicos. Ministério da Saúde. Secretaria de Ciência, Tecnologia e Insumos Estratégicos. Departamento de Ciência e Tecnologia. 2.ed. Brasília: Ministério da Saúde, 2010b. 44p. Disponível em: < h t t p ://bvsms.saude.gov.br/bvs/publicacoes/ classificacao_risco_agentes_biologicos_2ed.pdf>. Acesso em: 07 jul. 2011.

CENTERS FOR DISEASE CONTROL AND PREVENTION (CDC). Biosafety in microbiological and biomedical laboratories. 4.ed. Atlanta: U.S. Department of Health and Human Services, 2009. 250p. Disponível em: <http:// www.cdc.gov/biosafety/publications/bmbl5/BMBL.pdf $>$. Acesso em: 08 jul. 2011.

COSTA, M.A.F. Construção do conhecimento em saúde: estudo sobre o ensino de biossegurança em cursos de nível médio da área de saúde da Fundação Oswaldo Cruz. 2005. 154f. Tese (Doutorado em Biociências e Saúde) - Programa de Pósgraduação em Ensino de Biociências e Saúde, Instituto Oswaldo Cruz. Rio de Janeiro, RJ.
ENSERINK. M. The boom in biosafety labs. Science, v.288, n.5470, p.1320-1322, 2000.

HIRATA, M.H.; MANCINI FILHO, J.B. Manual de biossegurança. Barueri, SP: Manole, 2002. 495p.

MASTROENI, M.F. Biossegurança aplicada a laboratórios e serviços de saúde. São Paulo, SP: Atheneu, 2005. 338p.

PENNA, P.M.M. Biossegurança: uma revisão. Arquivos do Instituto Biológico, v.77, n.3, p.555-465, 2010.

SILVA, M.Z.M. A importância da biossegurança nos laboratórios de anatomia patológica dos hospitais públicos mediante o manuseio do formol. 2010. $62 \mathrm{f}$. Monografia (Especialização em Administração) - Programa de Pós-graduação da Faculdade de Economia, Administração, Contabilidade e Ciências da Informação e Documentação (FACE) da Universidade de Brasília. Brasília, DF.

SIMAS, C.M.; CARDOSO, T.A.O. Biossegurança e arquitetura em laboratórios de saúde pública. Pós, v.15 n.24, p.108-124, 2008.

TEIXEIRA, P.; VALLE, S. Biossegurança: uma abordagem multidisciplinar. 2.ed. Rio de Janeiro, RJ: FIOCRUZ, 2010. 442 p.

WORLD HEALTH ORGANIZATION (WHO). Laboratory biosafety manual. Geneva, 2004. 178p. Disponível em: <http://www.who.int/csr/resources/publications/biosafety/ Biosafety7.pdf>. Acesso em: 08 jul. 2011. 